\title{
La escucha en continuidad
}

\author{
CARMEN PARDO SALGADO
}

\section{AvatARES DE UNA SENSIBILIDAD MULTIPLICADA: LOS RUIDOS DE LAS MÁQUINAS}

Siguiendo a Walter Benjamin habría que situar el origen de la transformación actual de los modos de existencia y de la percepción en la época de la Modernidad. En ella encontraríamos que el continuo progreso de la ciencia y de la técnica da lugar a una práctica social y a un modo de vida que, unidos a la división social del trabajo, toma cuerpo en la noción de cambio, de una subjetividad en movimiento, en la referencia a la crisis y a la tensión de la vida moderna.

El término Modernidad aparece por primera vez en La Dernière Fée de Balzac en 1823 y encuentra una aplicación positiva en el ámbito estético con los escritos de Théophile Gautier y Charles Baudelaire en torno a 1850. En Le peintre de la vie moderne (1859), Baudelaire convierte el término Modernidad en el aglutinante de una estética y una poética nuevas, centradas sobre una toma de conciencia sin precedentes de la relación aparentemente contradictoria entre la belleza y el presente. La estética moderna toma cuerpo en esta tensión entre el ideal y lo nuevo, lo intemporal y el presente.

La Modernidad aparece para Baudelaire como lo transitorio, fugitivo y contingente y esto se convertirá a partir de ahora en el nuevo contenido del arte, lo que él denomina la mitad del arte; la otra mitad siendo todavía la belleza ideal, la belleza intemporal. El trabajo del artista moderno consistirá en extraer la belleza fugitiva, la belleza del presente. Esta belleza se encuentra por doquier en las calles del París de Baudelaire, en esas calles pobladas por gritos y traqueteos de carruajes que las convierten en ensordecedoras. En esas calles el poeta es un observador privilegiado que se abstrae de la masa para extraer la belleza: «iFinalmente! ; solo! Sólo se escucha la circulación de algunos coches de punto retrasados y derrengados. Durante algunas horas, poseeremos el silencio, si no el reposo. ¡Finalmente! la tiranía del rostro humano ha desaparecido, y no sufriré más que por mí mismo» ${ }^{1}$.

1 Ch. Baudelaire, «À une heure du matin», Le Spleen de Paris, Euvres Complètes, t. I, Paris : éd. De la Pléiade, Gallimard, 1975, X, p. 287. Cfr. también Le peintre de la vie moderne, op. cit., t. II, 1976, p. 695 ; «Tableaux parisiens» en: Les Fleurs du mal, op. cit., t. I. 
Baudelaire nos lleva a la experiencia del hombre que, finalmente, se aísla de la masa para volver a sí mismo. Se traza una línea que va del hombre multiplicado en la masa al hombre que mantiene su unicidad; del bullicio al silencio; del movimiento al reposo. Pero, de hecho, el poeta que narra el fragor de las calles de París, su aburrimiento, es siempre el hombre que observa, el hombre que se separa de la masa que pasea anónima y juega con su propia experiencia de las calles y el confundirse con la masa. El hombre que puede escribir estas líneas, es el que pasea desapercibido disfrutando del espectáculo de la masa, del privilegio de observar sin que esta acción sea a su vez observada.

La tensión entre lo intemporal y el presente, imposibilitará la comprensión de la experiencia de lo vivido en tanto totalidad y sitúa la noción de fragmentación como categoría central de la Modernidad, tal y como por ejemplo se muestra en Benjamin y Th.W. Adorno. Se trata en estos autores de una fragmentación manifiesta en la obra de arte y en la percepción y que se corresponde con lo que Benjamin denomina la pobreza de la experiencia ${ }^{2}$.

Esta tensión entre la belleza y el presente, entre lo ideal y lo nuevo tendrá, entre otras consecuencias, una estetización de lo cotidiano que encontrará sus primeras manifestaciones en la moda y en las Exposiciones Universales. La estetización de lo cotidiano, alimentada por un sistema político-económico que la amplificará, se encuentra en el origen de lo que hemos denominado la estetización de lo social, es decir, la extensión de la estetización a todas las instancias de la vida.

Atender al modo en que esta estetización afecta a lo sonoro y produce la escucha en continuidad, obliga a interrogar la relación del ámbito musical con los cambios que Baudelaire evoca en las calles de París, así como con su relación con las máquinas que proporcionan las nuevas tecnologías.

El manifiesto futurista $\mathrm{El}$ arte de los ruidos, escrito por Luigi Russolo en 1913, permite establecer el nexo entre la percepción de esas calles ensordecedoras y las máquinas que van unidas a esos sonidos. Este nexo será fundamental para la posterior concepción y evolución de la práctica musical.

En las primeras líneas del manifiesto se encuentra la siguiente afirmación: «La vida antigua fue toda silencio. En el siglo diecinueve, con la invención de las máquinas, nació el Ruido. Hoy, el Ruido triunfa y domina soberano sobre la sensibilidad de los hombres. Durante muchos siglos, la vida se desarrolló en silencio o, a lo sumo, en sordina. Los ruidos más fuertes que interrumpían este silencio no eran ni intensos, ni prolongados, ni variados. Ya que, exceptuando

2 La pobreza de la experiencia tal y como Benjamin la expone en su texto Experiencia y pobreza de 1933 permite mostrar el paso de una civilización del trabajo y el progreso a una civilización del consumo y el placer. Se trata de una civilización que dará lugar a lo que Adorno y Max Horkheimer denominan la industria cultural. 
los movimientos telúricos, los huracanes, las tempestades, los aludes y las cascadas, la naturaleza es silenciosa» ${ }^{3}$.

La apreciación de Russolo es certera, aunque la vida en la antigüedad no transcurriera en silencio, ni tampoco la naturaleza sea silenciosa. Ciertamente, el ruido gobierna la sensibilidad de los hombres, no sólo en la ciudad, también en el campo. No obstante, el silencio del que habla Russolo resulta familiar, se trata simplemente de aquel silencio que se siente por ejemplo en la sala de conciertos cuando la música cesa, lo que se oye cuando se deja de escuchar.

El silencio de la vida estaba cubierto por los sonidos que los hombres arrancaban a las cañas, las pieles, la madera, y después a los metales, creando orquestas que deleitaban los oídos, dando nacimiento a la música. Después, con las máquinas, surgirán los ruidos que vendrán a poblar las ciudades y las salas de conciertos. Los ruidos exhiben una gran variedad de tonos que provocan, según Russolo, que los antiguos sonidos musicales se perciban como «monótonos», sin vida. Frente a la monotonía de la música anterior, el oído «educado por la vida moderna», percibe el sonido-ruido como cargado de sensaciones y emociones inesperadas que, sin duda, contribuirán aún a alterar la sensibilidad de los hombres.

Los ruidos de la vida moderna son excitantes; mueven al oyente y lo hacen salir de sí mismo. Frente a la escucha concebida como pasaje sonoro por la interioridad, la escucha de los ruidos obliga a un paseo por la exterioridad, por el afuera que es la ciudad y que impone otro tipo de exposición, de experimentación.

La tensión que Baudelaire señalaba entre la belleza ideal y el presente desaparece en el manifiesto futurista para el que el pasado debe ser ignorado porque no es capaz de expresar la riqueza de la vida moderna. La evolución de la música que el futurismo propugna apuesta en consecuencia, por un proceso de borrado en el que los sonidos-ruidos puedan inscribirse a partir de cero. Los oídos futuristas están preparados para encontrar esa belleza fugitiva y contingente. Para ellos, todo el contenido del arte.

El ruido se caracteriza, como es sabido, por las vibraciones irregulares en tiempo e intensidad, una irregularidad que ocupa hoy las calles. Lejos de los tintes negativos que esta valoración pueda inducir, para Russolo se trata de una alteración que pone al descubierto una capacidad inédita para recibir sensaciones que, a su vez, suscitan emociones antes insospechadas. De este modo, el ruido que surge de lo mecánico estaría produciendo una lenta diversificación del conjunto de los órganos sensitivos y especialmente del oído.

Desde el oído el hombre transformará su relación con el entorno y consigo mismo, por eso el ruido remite a la vida. El desarrollo de la vida se va a unir

3 L. Russolo, El arte de los ruidos, tr. O. y L. Alas, Cuenca: Centro de Creación Experimental de la Universidad Castlilla-La Mancha, 1998, p. 7. 
al de la máquina, tal y como se manifiesta actualmente en la vida de cualquier gran ciudad.

Si Baudelaire ofrece la figura del flâneur que recorre las calles de París con su mirada, Russolo apuesta por un paseante que haga de sus oídos el sentido primordial. Así propone:

Atravesemos una gran capital moderna, con las orejas más atentas que los ojos, y disfrutaremos distinguiendo los reflujos de agua, de aire o de gas en los tubos metálicos, el rugido de los motores que bufan y pulsan con una animalidad indiscutible, el palpitar de las válvulas, el vaivén de los pistones, las estridencias de las sierras mecánicas, los saltos del tranvía sobre los raíles, el restallar de las fustas, el tremolar de los toldos y las banderas. Nos divertiremos orquestando idealmente juntos el estruendo de las persianas de las tiendas, las sacudidas de las puertas, el rumor y el pataleo de las multitudes, los diferentes bullicios de las estaciones, de las fraguas, de las hilanderías, de las tipografías, de las centrales eléctricas y de los ferrocarriles subterráneos. ${ }^{4}$

En cualquier calle de una ciudad se escucha alguno de estos ruidos, y ahora también otros. Pero en esta lista destaca sin duda ese «rugido de los motores» con «una animalidad indiscutible». La «indiscutible animalidad» será la vida que transmite el ruido, una animación de un signo diferente que emerge de la variedad, la cantidad y la riqueza de sonidos que ofrecen las calles. La irregularidad y riqueza del ruido es la causa, entre otras, de que los ruidos de la ciudad no tengan nombre, la causa de esta animalidad anónima que pertenece al hombre de la calle, al hombre que es movido por las intermitencias del ruido.

Las válvulas, las sierras mecánicas o el restallar de las fustas van a formar parte de una orquesta insospechada. La música se enriquecerá con esta animación aún indefinida dando paso a una orquesta de ruidos. El mismo Russolo, en colaboración con el músico Ugo Piatti, construyó los entonarruidos u órganos de ruidos, unas máquinas capaces de emular algunos sonidos de la vida cotidiana.

El primer entonarruidos es un explotador que reproduce el ruido del motor de explosión, pudiendo modificar su tono en dos octavas. A él le seguirán los aulladores, fuelles, zumbadores, tronadores, silbatos, gritadores, gemidores o los sollozadores. Con estos nuevos instrumentos se compusieron obra como El despertar de una ciudad; Cita de automóviles y aeroplanos, o Comiendo en la terraza del hotel, cuyos títulos son altamente significativos.

Los órganos de ruidos de Russolo y de Piatti parten del presupuesto de la imitación de los ruidos de la vida moderna. En este sentido, no implican una novedad para el ámbito musical que, aunque siempre partiendo del trabajo

4 L. Russolo op. cit., pp. 10-11. 
compositivo, había acudido de vez en cuando a emular los sonidos de la vida cotidiana. La diferencia respecto al modo en que esto es realizado es sin embargo abismal. Si en las obras de Janéquin o Puccini se trata de introducir algún sonido de la naturaleza en una obra -compuesta básicamente con sonidos artificiales surgidos de los instrumentos musicales máquinas al fin-, con los órganos de ruidos el objetivo es reproducir esos sonidos sin integrarlos con los sonidos musicales. El resultado es que el trabajo compositivo mismo será modificado por los ruidos de la vida moderna.

Los órganos de ruidos se encuentran en sintonía con ese hombre de la muchedumbre del que hablaba Baudelaire. En el retrato de M.G. que lleva a cabo en Le peintre de la vie moderne -ese pintor que oculta su nombre-, Baudelaire expone cómo mientras el resto duerme, este pintor quiere lanzar sobre el papel la misma mirada que antes había depositado sobre las cosas. Finalmente, «las cosas renacen sobre el papel». Del mismo modo, el hombre que atraviesa la ciudad con los oídos, hace de los órganos de ruidos los instrumentos del renacer de los ruidos de la vida moderna.

Desde la escucha de las calles y desde la creación de instrumentos que dan cuenta de esos sonidos, Russolo puede afirmar que la «evolución de la música es paralela al multiplicarse de las máquinas, que colaboran por todas partes con el hombre» 5 .

En el rumor de las calles se trazan dos líneas que Russolo pone en paralelo: la evolución de la música y el multiplicarse de las máquinas. En la resonancia de esas dos líneas se gesta lo que Russolo denomina una sensibilidad multiplicada que, se nos dice, tendrá oídos futuristas, oídos orientados hacia el futuro. De la monotonía que suponía para los oídos futuristas el ámbito de la música tonal se pasa a la variedad y riqueza de los sonidos de las máquinas. Con ello, la distinción entre sonidos musicales y sonidos de la vida cotidiana se irá lentamente borrando.

La evolución de la música y las máquinas corre en paralelo porque, de hecho, la música exhibe un carácter maquinal. Este carácter maquinal de la música lo explicita espléndidamente Georges Antheil cuando afirma: «Presumo que la música es el arte más adecuado para expresar las mejores cualidades de la máquina. La máquina forma parte de nuestra vida, es bueno que los hombres experimenten sentimientos hacia ella. El arte sería débil si no pudiera tratar este nuevo contenido» ${ }^{6}$.

$5 C$ Cr. L. Russolo, op. cit., p. 8. Se destacará sin embargo que la música siempre ha integrado los sonidos de la calle, las irregularidades, los gritos, como por ejemplo en el quodlibet dejado por Cl. Janequin en Les cris de Paris (1540) o G. Puccini en La Bohème (1896). 622.

6 Cit. por E. Pound, «Georges Antheil», tr. M. Beaujour, Les Cahiers de l'Herne, 2, p. 
Si la música es el arte más adecuado para expresar las mejores cualidades de la máquina, es porque la música, en gran manera, surge con el artificio de los instrumentos a ella destinados. Hasta la voz hecha música muestra el arco que conduciría de lo natural al artificio. Pero Antheil, cuando se refiere a la máquina piensa en un nuevo contenido porque la máquina no es ya el instrumento musical, sino la máquina industrial: el motor. No en vano el primer órgano de ruidos es un explotador.

En este marco se inicia el lento acercamiento que conducirá, tal y como proclamarán las primeras vanguardias, del arte a la vida, a su indistinción. No se trata entonces del nexo de la música con un instrumento diseñado para ella, sino de las relaciones que se van a establecer entre la música y los instrumentos que pueblan la vida cotidiana en las fábricas o en las calles. La música viene a engarzarse con un modo de vida, con una sensibilidad que es la que engendra un sistema económico determinado como es el capitalismo.

Se dirá que esto siempre ha sido así, que la música ha sido reflejo de la organización social de un Estado. Tal vez, pero lo que se ha modificado en profundidad no es sólo su consideración como reflejo, sino los mecanismos por los cuales este reflejo es producido. Estos mecanismos, los de la composición misma, son afectados desde el origen -el sonido-, hasta las relaciones que éstos establecen entre sí. Tal modificación, a tanta profundidad, no había tenido lugar en la historia de la música europea.

No sólo los oídos futuristas pronosticaron que la evolución de la música sería paralela al multiplicarse de las máquinas, también oídos como los de John Cage en su Futuro de la Música: Credo lo afirmaba en 1937:

1. La música es organización de sonidos.

2. La organización del sonido incluirá el ruido y con él toda la música de percusión.

3. La organización del sonido se realizará asimismo en centros de música experimental donde se producirá música sintética ${ }^{7}$.

Aquel futuro de la música es hoy nuestro presente, y muestra que las dos líneas paralelas que Russolo dibujara, encontraron ese punto en el que pueden

7 Esta conferencia se publicó en su obra Silence, Hanover: Wesleyan University Press, 1973 (1961). Existe traducción castellana en J. Cage, Escritos al oído, Murcia: Colegio Oficial de Aparejadores y Arquitectos Técnicos, Colección de Arquilectura, 1999 y en J. Cage, Silencio, Madrid: ed. Árdora, 2002. Tal y como Cage predijo, la organización del sonido se llevó a cabo asimismo en centros de música experimental dando nacimiento a la música concreta en 1948 por Pierre Schaeffer y Pierre Henry en el Centro de la Radiodifusión de París y a la música electrónica en 1950 por Herbert Eimert en el estudio de Colonia. Para un desarrollo de esta cuestión cfr. C. Pardo, «La sensibilidad de la máquina: el circuito sonoro», Acto. Revista de pensamiento artístico contemporáneo, La Laguna, $\mathrm{n}^{\circ}$ 1, 2002, pp. 43-55. 
coincidir, que los motores y las máquinas fueron «sabiamente entonados». De ello han sido muestra desde los primeros conciertos que introducen los sonidos de la calle y de las fábricas, como la sirena que hace escuchar Edgar Varèse en su obra Ionisation (1931), hasta el amplio abanico de la música techno surgida del paisaje post-industrial en el Detroit de mediados de los ochenta y extendida a un nivel casi planetario, pasando por Throbbing Gristle, primer grupo de la Música Industrial fundado por Genesis P. Orridge en 1975 y que parte del ruido como material de la creación musical. Las fábricas no son solamente los lugares de los que surge la nueva orquesta, las fábricas son ahora espacios para ocupar y bailar; lugares de apropiación y desviación; lugares aptos para el recubrimiento artístico ${ }^{8}$.

La apertura de la sensibilidad que Russolo pronosticaba ha seguido su proceso de multiplicación. Se trata de una sensibilidad que consiste en un acrecentamiento que sitúa todo en un mismo plano de convivencia, dando entrada a la riqueza y a la multiplicidad que crea el ruido, generando emociones, movimientos internos y externos que van a suponer una forma inusitada de estar en el propio cuerpo y en el mundo. Se trata de una sensibilidad que no sigue un recorrido único e intencional que, simplemente, tiende el oído a lo que acontece.

Las partituras de lo audible que ofrecen estas músicas, indican desde hace un tiempo que las calles forman parte del gran laboratorio del presente, que el oído futurista es oído del presente, repeticiones de lo efímero que indican la evacuación de un mapa, paisaje, territorio, un lugar con nombre o con sentido previo. Es lo que está repitiendo hasta la saciedad parte de la música de nuestro tiempo, la música que sabiamente entona los ruidos de las máquinas y de las calles.

Las máquinas modernas han contribuido a que, finalmente, se haga de la vida y el arte un solo espacio, aunque en este hacer la vida se haya ido recubriendo con la pátina del arte. Con ello, el lento proceso de estetización que había hecho de la moda y las Exposiciones Universales sus primeros síntomas, encuentra en la máquina y en su particular nexo con la música un catalizador positivo.

\section{AvataRes DE UNA SENSIBILIDAD MULTIPLICADA: MEDIOS DE REPRODUCCIÓN SONORA}

La escucha de las calles es la escucha de la vida moderna, de las máquinas que la componen y que conducen a esa sensibilidad multiplicada. Pero a las máquinas de los futuristas se debe añadir no sólo los instrumentos con los que

8 Para un estudio de las relaciones entre arte y trabajo ver: O. Comeron, Arte y postfordismo. Notas desde la Fábrica Transparente, Madrid: Trama, 2007. 
se compone asimismo la música en la actualidad sino también y, sobretodo, los instrumentos de reproducción que tanto han contribuido al desarrollo de lo sonoro: la radio y el disco en primer término. Ambos serán instrumentos mayores de una escucha en continuidad inaugurada en las calles de las grandes ciudades y ejemplos más evidentes de esa estetización en lo que concierne a lo sonoro.

Los medios de grabación y reproducción llevarán a cabo lo que Paul Valéry denomina la conquista de la ubicuidad. Por doquier las imágenes visuales y sonoras vendrán a alimentar los sentidos del hombre del siglo XX. Es preciso recordar a este propósito que, en 1906, se termina de fabricar el Telarmonio, primer instrumento electrónico que enviará música a hoteles, restaurantes y domicilios particulares a través de la línea telefónica a petición del interesado y previo pago. Se trata de lo que podríamos denominar el primer hilo musical. Se hará realidad entonces lo que Valéry denomina el sueño de una «distribución de Realidad Sensible a domicilio». Esta distribución implica, para Valéry, la posibilidad de acceder a una experiencia individual en el momento en que el oyente lo desea, sin esperar a la hora fijada para el concierto. Por ello, el escritor llegará a afirmar que «el trabajo del artista músico, autor o virtuoso, encuentra en la música grabada la condición esencial del rendimiento estético más alto» ${ }^{9}$. La elección por parte del oyente del momento y del repertorio que desea escuchar, aparecen como la garantía de una fruición individual que acerca el trabajo del oyente al del artista.

La reproducción implica, para Valéry, la transposición del sistema de excitaciones que dispensa la obra sonora o el objeto en cuestión. Se podría objetar que este sistema no tiene por qué repetirse cada vez que se escucha la obra, que las sensaciones pueden ser otras. Sin embargo, es sabido que la mayoría de oídos que practican una escucha reiterativa tienen como objetivo, justamente, la repetición de lo sentido. De hecho, más allá de la obra se tiende a reproducir ese sistema de excitaciones que establece el nexo entre lo escuchado y el escucha. A la reproducción de la obra le corresponde la reproducción de las sensaciones.

La distribución de la realidad sensible a domicilio, supone el paso de una escucha colectiva a la escucha individual, aun cuando en un primer estadio esta escucha siguiera siendo colectiva dado el precio de los aparatos de reproducción. La escucha individual -en lo que se refiere a la música-, acabó convirtiéndose en una reproducción primero de ese sistema de excitaciones que la obra provoca y, en segundo lugar, en la producción de un tipo de escucha modelada por el aparato mismo que imponía en su origen, el tiempo de duración de una canción y un modo interpretativo determinado en la grabación.

9 P. Valéry, «La conquête de l'ubiquité», Pièces sur l'art, en: Oeuvres, vol. II, Paris : Bibliothèque de la Pléiade, 1962, p. 1285 y 1286. 
En el caso de la radio, transformada después de la Primera Guerra Mundial en países como Estados Unidos o Alemania, en aparato de consumo doméstico, la transmisión de la música va unida a la de los mensajes políticos y morales a los cuales la música misma no resultará ajena. Lo que aquí denominamos la escucha en continuidad empieza a mostrar desde estos objetos de consumo, el proceso de estetización al que terminará siendo sometida.

La radio ofrece la primera imagen sonora del mundo. La escucha colectiva de los primeros medios de difusión masiva no es la escucha colectiva de la sala de conciertos. Lo que se colectiviza es la experiencia de un mundo que se transmite por las imágenes sonoras que van desde la voz que enuncia las noticias hasta la música de moda. La radio convoca e invoca al oyente a un mundo común, el de la imagen sonora que ella produce.

La publicidad de los primeros aparatos de radio era clara a este respecto: $E s$ cuchar es sentir el mundo ${ }^{10}$. La comprensión y compresión del mundo pasa por la gestación de una primera imagen sonora que se convertirá como es sabido, en arma política. Aunque el control del espectro de ondas, que hasta los años 20 del siglo anterior había estado en manos de la marina y la policía, acabara entregándose al comercio, el Estado decidió que debía seguir ejerciendo un control. De este modo, quedaban regulados desde la amplitud de frecuencia que los usuarios podían captar hasta el tipo de música que se podía reproducir. Como Benjamin lo expuso, a la reproducción en masa le corresponde una reproducción de las masas.

La radio, como el disco, implican el consumo multiplicado de lo que se dará en llamar productos culturales. A estos medios de reproducción masiva le responde la producción en serie de consumidores y una progresiva uniformidad de la sensibilidad y el imaginario. Así, la sensibilidad multiplicada que auguraban los futuristas se aviene con la multiplicación de diversos tipos de sensibilidad ensayados por parte de los medios de reproducción.

La radio, para McLuhan medio cálido que requiere poca participación, es capaz de transformar la psique y la sociedad en una caja de resonancia. La radio es una tecnología que implica el fortalecimiento de la unión entre los hombres. Por ello, es considerada por McLuhan como un tambor tribal que tiene la capacidad de devolver al hombre individual a la tribu ${ }^{11}$. Pero la masa del presente no es la tribu. La masa es anónima, sin vínculos familiares y sin una conducta que responda a una autoridad que mantiene la tradición. La masa tardará tiempo en crear la presencia de vínculos que, en su interior, identifique a parte de sus com-

$10 C f r$. H. Eck, «La radiodifusión dans l'entre-deux-guerres: l'invention d'une culture médiatique singulière», en : J.-Y. Mollier, J.-F. Sirinelli , F. Valloton, Culture de masse et culture médiatique, Paris: PUF, 2006, p. 234.

$11 C f r$. M. McLuhan, «Radio, el tambor tribal», Understanding Media: The Extensions of Man, Nueva York: Mc Graw Hill, 1965. 
ponentes como tribu, tribu urbana que deberá ser siempre declinado en plural para atender a su multiplicidad. No obstante, si la radio puede ser considerada como el tambor tribal es por su capacidad para evocar la autoridad de lo que debe ser sabido y reconocido, lo que antes pertenecía al anciano de la tribu.

Este tambor tribal que transforma a la sociedad en una caja de resonancia, hará que la radio se pueda convertir en un arma tanto del fascismo como del comunismo. También un arma de todos aquellos que más allá de estos istmos hicieron de ella un instrumento de propaganda, fuera lo que fuera lo que debía ser propagado.

En 1921 Velimir Khlebnikov escribe La radio del futuro, un manifiesto que hace de la radio una herramienta de propaganda para informar, educar y unir al pueblo. Dziga Vertov en 1925 pretende hacer de la radio el arma revolucionaria de comunicación auditiva entre el proletariado, mediante las grabaciones de sonidos de los lugares de trabajo y de la vida cotidiana. La radiodifusión de los sonidos de la calle y de las fábricas obliga a pasar de la multiplicación de la sensibilidad propugnada por los futuristas a su consideración como símbolos de reconocimiento del proletariado. En el otro extremo, se encuentra el aparato del III Reich regulando la música que el pueblo puede escuchar y radiando los discursos del Führer para gestar el alma colectiva necesaria al sistema.

La radio, tambor tribal que multiplica la voz, se quiere hacer también participativa. Al tiempo que se produce el uso militar de la radio, particularmente en el periodo de entreguerras y durante la Segunda Guerra Mundial, surge el interés de las vanguardias por este nuevo medio. Así, en México, la aparición de la radio y el estridentismo se producen al mismo tiempo. Manuel Maples Arce, su máximo representante, inaugura con un poema la emisora La voz de América Latina en marzo de 1923.

Bertolt Brecht propone en su Teoría de la radio (1927-1932), el paso de la radio concebida como aparato de distribución a aparato de comunicación que transforme al radioescucha en un hablante ${ }^{12}$. En la misma línea se sitúan los Hörmodelle de Benjamin o modelos de escucha que el filósofo dictaba para la radio de Frankfurt entre 1929 y 1932. En ellos se partía de situaciones de la vida cotidiana en los que se mostraba un ejemplo y un contraejemplo que acentuaban la necesidad del carácter dialéctico de la escucha.

Para estar voz multiplicada que es la radio se hicieron también los primeros trabajos de radio-arte. En 1933 Filippo Tommaso Marinetti y Pino Masnata escriben el manifiesto La Radio, donde se destaca la especificidad del lenguaje radiofónico. Para entonces el primero ya había radiado el Bombardeo de Adrianapoli y el también futurista Fortunato Depero lleva a cabo su experiencia radiofónica en Radio Milano. Trataba de conseguir a través de los ruidos, de 
las onomatopeyas u otros sonidos inventados, hacer sentir al oyente como si estuviera en la cubierta de un barco o viajando en un aeroplano. En una de las líricas radiofónicas de Depero se lee:

El oyente ya no está solo, recogido

en un salón silencioso y romántico, sino que se encuentra

en todas partes: por la calle, en los cafés, en un avión, en los

puentes de los barcos, en mil atmósferas diferentes ${ }^{13}$.

El oyente se multiplica desde su hogar. La ubicuidad que le aporta la imagen sonora lo devuelve a la experiencia colectiva, al anonimato también. Se consuma con la radio, la abolición de tiempo y espacio propugnada por los futuristas.

Para 1933 el dadaísta Karl Schwitters había grabado sus poemas fonéticos para la Süddeutsche Rundfunk de Francfort. Mientras, Ramón Gómez de la Serna se convertía en radio-reportero y escribía para la revista Ondas sobre la «variedad y belleza de los pitidos» ${ }^{14}$. Las crónicas de lo cotidiano de Gómez de la Serna se convertían para su propia vida diaria en grafías sonoras del silencio, del aire de la ciudad. «Muchas veces, en horas sin posibilidad de emisiones, dejo abierto mi aparato para saber cómo respira electrónicamente el aire, como bulle el sistema nervioso» ${ }^{15}$. La escucha de la ciudad y con ella la ciudad misma, se transforma con las máquinas.

A ellos se sumarían Kurt Weill proponiendo un radio-arte absoluto o Antonin Artaud con su censurado Pour en finir avec le jugement de Dieu de 1947.

Para el radio-arte la voz multiplicada no debe limitarse a narrar historias, a ofrecer consignas, sino también tiene que hacer sonar la vida: la animalidad de una voz, los susurros del viento o del agua, el crepitar de las hojas o el chirriar de una puerta al moverse. La radio puede ser de hecho un instrumento musical, como lo pone de manifiesto John Cage con su Imaginary Landscape $n^{\circ} I$ (1939), que evidencia la idoneidad que el músico encuentra entre los sonidos de radio y percusión.

13 G. Scuderi, S. Castiglione, E. Mazza, «Futurismo italiano (1909-1944)», en: Ruidos y susurros de las vanguardias. Reconstrucción de obras pioneras del arte sonoro (1909-1949) por el Laboratorio de Creaciones Intemedia, Valencia: UPV, 2004, p. 50.

$14 C f r$. R. Gómez de la Serna, «Radio Humor: Greguerías onduladas» en J.A. Ventín Pereira, Radiorramonismo. Antología y estudio de textos radiofónicos de Ramón Gómez de la Serna, Madrid: Universidad Complutense, 1987, p. 153.

15 M. Molina Alarcón, «Ramonismo (1915-1936)», Ruidos y susurros de las vanguardias, op. cit., p. 118. 
En el radio-arte de los inicios, arte y entorno resuenan en la misma frecuencia. Pero el mismo objetivo es el que persigue el uso político de la radio aunque, en este caso, el entorno sea generado por la ideología. El continuo sonoro al que apuntan unos y otros es de carácter disímil pero esa continuidad ha ido impregnando lentamente la escucha. Desde todos los ámbitos se tuvo conciencia de que lo que había en juego era la posibilidad de acuñar un tipo de escucha que sería repetida, multiplicada por la técnica. Ese tipo de escucha podía ser un campo abierto para la transmisión de consignas políticas o para la transmisión musical y todo cabía en la misma frecuencia que las ondas permitían. La escucha que se deja seducir, la que se hace dialéctica, la que atiende a los sonidos olvidados por los siglos de cultura visual, la escucha atenta y distraída; todas fueron ensayadas ante la intuición de que, como más tarde afirmaron Edmund Carpenter y McLuhan, la humanidad retornaba de nuevo al espacio acústico ${ }^{16}$.

Dentro del mismo medio todas esas escuchas resultaron una apuesta. Por ello pensamos que, aunque la afirmación de Theodor W. Adorno que «toda la vida musical actual está dominada por la forma mercantil» ${ }^{17}$, fuera absolutamente cierta, aún así no parece que en la actualidad, pueda seguir distinguiéndose entre una escucha regresiva que sería asignada a la música de los media y una escucha atenta que pertenecería a las músicas de las vanguardias o experimentales. Para el filósofo, no hay diferencia entre la escucha de la música ligera -que sólo repetiría modelos ya dados-, y la de la Séptima Sinfonía de Beethoven a través de la radio: «El significado de una sinfonía de Beethoven escuchada mientras el oyente está paseando o recostado en la cama es muy probablemente distinto del efecto que llega a tener en una sala de conciertos donde la gente está sentada como en una Iglesia. ¿Escuchan la música sentados, de pie, caminando o acostados en la cama? ¿La escuchan antes, durante o después de las comidas? [...] Si la música se está convirtiendo en una suerte de función diaria, estará por cierto muy estrechamente ligada a las comidas. Y si la gente intenta reducir la distancia entre ellos y la música incorporándola, por así decir, dentro de sí mismos, y si la tratan como una especie de producto 'culinario', es posible demostrar que todo esto guarda una relación determinada con el comer» ${ }^{18}$.

La música a través de la radio cubre una función para Adorno que no es ya la de una obra de arte. La escucha se practica al mismo tiempo que otras

16 Cfr. E. Carpenter, M. McLuhan, «El espacio acústico», en: El aula sin muros. Investigaciones sobre técnicas de comunicación, tr. L. Carandell, Barcelona: ed. de Cultura Popular, 1968.

17 Th.W. Adorno, «Sobre el carácter fetichista en la música y la regresión del oído», tr. R. de la Vega, en: Disonancias, Madrid: Rialp, 1966, pp. 64, 69-70.

18 Th. W. Adorno, Music in Radio, Archivo de la Universidad de Columbia, p. 132. Citado en: M. Molina y L. Amigo, «Agit-prop y pensamiento crítico (1918-43). Música en la radio», en: Ruidos y susurros de las vanguardias, op. cit., p. 101. 
actividades de la vida cotidiana por lo que la escucha de lo musical pierde ese carácter sagrado que tiene para el filósofo, como en un Iglesia. Pero, si es cierto que el oyente moderno se halla retenido en un infantilismo que se caracteriza para Adorno por una escucha atomizada, por la disociación -lo que Benjamin había enunciado como percepción en la distracción-, parece que debiéramos afirmar que esta disociación puede darse asimismo entre los distintos tipos de escucha y en el mismo oyente, pero todo ello en continuidad. Realizada la multiplicación de la sensibilidad que pronosticaron los futuristas, podemos afirmar que se puede mantener una escucha regresiva en una sala de conciertos y una escucha atenta en el sofá de casa, aunque en el segundo caso, la unicidad de tiempo y espacio en el que la obra se transmite haya saltado en pedazos.

\section{LA ESCUCHA EN CONTINUIDAD}

Los avatares de la sensibilidad multiplicada alcanzan con las tecnologías de grabación y reproducción un alcance insospechado. Todos los intersticios de la vida social e individual en los países industrializados serán ocupados por el fragor de las ondas. El temor que expresa Valéry cuando -recordando un espectáculo maravilloso al que asistió de niño y donde todos los muebles hablaban y cantaban-, afirma que espera que no lleguemos a ese exceso de magia sonora, se ha cumplido. Y es que, como el mismo Valéry explica, no se puede estar en un café sin ser sorprendido por un concierto ${ }^{19}$. Se podría pensar que Valéry exagera pero para desmentirlo, sólo tendríamos que traer a la memoria que, por ejemplo, desde el invento del Telharmonium en1906 los restaurantes de Estados Unidos llenan sus comedores con su música.

Si recordamos que el texto de Valéry se publica por vez primera en 1928, podemos hacernos una ligera idea de la multiplicación que se ha operado en nuestros oídos y, con ellos, en todo nuestro sistema sensible.

De los cafés y restaurantes a los servicios médicos, el transporte público, las esperas al teléfono o los centros comerciales, la multiplicación de lo sonoro por medios eléctricos viene a sumarse a los ruidos de las calles. A todo ello, aún se añadiría la connivencia entre los sistemas de producción y reproducción sonora con un sistema económico fundado en unas multinacionales de alcance planetario. Nos situaríamos ante ese fenómeno que a falta de un nombre mejor designamos como globalización ${ }^{20}$.

19 P. Valéry, op. cit., p. 1286.

20 En lo que a música se refiere, eso que denominamos global inicia su andadura con las primeras Exposiciones Universales y el consiguiente descubrimiento de otras músicas. La Exposición Universal de 1889 en París es la primera que producirá un impacto considerable 
La música en continuidad en los cafés, restaurantes, centros comerciales que son también de ocio, servicios médicos, transportes públicos... y la continuidad territorial que supone lo global son la cara y el envés de un mismo fenómeno: los nexos que las tecnologías tejen con el proceso social, económico y político. A la continuidad de lo sonoro le responde la continuidad de la escucha y ambas acogen en su seno lo que antes constituían polaridades: arte y vida; música culta y popular; escucha atenta y distraída. Erik Satie fue en este sentido un visionario al proclamar su música de ambiente o Muzak (musique d'ameublement), estableciendo los nexos entre lo industrial y lo musical que los futuristas obviaban:

Mobiliario musical

La 'Música de Mobiliario'-es básicamente industrial. Por costumbre -usualmente- se pone música en ocasiones en que la música no pinta nada. Por ejemplo, se tocan 'Valses', 'Fantasías' de Ópera \& otras cosas parecidas, escritas con otro objeto.

Nosotros queremos lanzar una música compuesta para satisfacer las necesidades 'útiles'. El Arte no entra dentro de esas necesidades. La 'Música de Mobiliario' crea vibración; no tiene otra finalidad; desempeña la misma función que la luz, el calor \& el confort en todas sus formas.

La ‘Música de Mobiliario’ reemplaza ventajosamente las Marchas, Polcas, Tangos, Gavotas, etc.

Exijan la 'Música de Mobiliario'.

No más reuniones, asambleas, etc., sin 'Música de Mobiliario'.

'Música de Mobiliario' para notarios, bancos, etc....

La 'Música de Mobiliario' no tiene precedentes.

Ninguna boda sin 'Música de Mobiliario'.

No entre en una casa en que no se utilice la 'Música de Mobiliario'.

Quien no haya escuchado todavía la 'Música de Mobiliario' no conoce la felicidad.

en lo que se refiere al ámbito musical. Allí se exponen instrumentos y se interpretan músicas de Java, de África y de España entre otros. Es bien conocida la influencia del gamelan de Java sobre la música de Claude Debussy y la asimilación de la música española con lo exótico. La afluencia masiva a estas exposiciones - treinta y dos millones de entradas vendidas para la de 1889-, dan buena cuenta de un fenómeno que bien podemos situar como precursor de esto que ahora es llamado globalización.

Si el manifiesto de Russolo y el trabajo de tantos músicos condujo a hacer realidad que la evolución de la música corre paralela a la multiplicación de las máquinas, también la escucha de la música de otras culturas contribuyó, en un primer momento, al descentramiento de la música tonal. Respecto a esta cuestión cfr. M. Solomos, «Aspectos de una 'alter-mundialización' musical», en: Contrastes. Otra globalización, no 48, Valencia, 2007, pp. 41-45. 
No se duerma sin escuchar un fragmento de 'Música de Mobiliario' o dormirá usted $\mathrm{mal}^{21}$.

El exceso de magia sonora por el que los muebles hablan llega hasta la misma consideración de la música como aquello que forma parte del mobiliario. Ninguno de los espacios pensados por Satie escapa a la «Música de Mobiliario» y aún podríamos añadirle algunos más.

Esta música es calificada por Satie como industrial y este adjetivo no tiene nada que ver aquí con el tipo de sonidos utilizados para la composición. No se trata de la incorporación de los ruidos de la vida moderna. El adjetivo industrial denota esa capacidad de la música para «satisfacer las necesidades 'útiles'». Estas necesidades son, siguiendo a Satie, las que procuran el confort.

La «Música de Mobiliario» crea vibración, afirma Satie. La música expande un ritmo, un tono que, se podría pensar, puede ser mantenido a distancia, como si se tratara de una música de fondo contra la cual el oyente se destaca. Pero aún con ello, el objetivo de la música como mobiliario es doble:

1. Procurar el esparcimiento del oyente, su falta de concentración sobre lo que acontece, ya sea la espera para entrar al dentista, un trayecto en tren, el despegue y el aterrizaje de un avión, etc.

2. Superponer al ambiente creado por las condiciones del espacio y la concentración humana, una prótesis sonora en la que todos los oyentes queden integrados: el espacio de un aeropuerto, un gran centro comercial...

A estos dos objetivos se podría añadir el deseo de hacer de la prótesis sonora un elemento inconsciente que activaría el consumo en los centros comerciales, como las calles con megafonía y ornamentos lumínicos en Navidad..., aunque su eficacia no esté probada.

La «Música de Mobiliario» aparece como una necesidad útil. La música es un mueble, sonido difundido en un espacio ocupado a su vez por otros muebles, mientras los oyentes se afanan por llevar a cabo sus tareas o simplemente se intentan relajar. Esta música-mueble se convierte en herramienta, en útil que convierte a los oyentes en mediación. La escucha se transforma en medio para conseguir un ambiente, un cierto tono común que conduce a un estado. Lo que teje el hilo musical es el estado en el que se quiere amansar al oyente.

21 E. Satie, Memorias de un amnésico y otros escritos, tr. L. Casado, Madrid: Fugaz, ed. Universitarias, 1989, pp. 111-112. En la actualidad se suele traducir musique d'ameublement por música ambiente aunque la explícita referencia a la música como un mueble más queda mejor recogida con la traducción que aquí se ofrece. 
La presión acústica ejercida con esta música crea estados que se sustentan, sobretodo, por el esparcimiento o la dispersión que, en mayor o menor grado, deben producir sobre el oyente, aunque sea simplemente porque lo que está sonando no es de su agrado y pretende escapar a ello.

La ubicuidad de esa magia sonora viene a ocupar todos los resquicios de la vida pública proclamando, en apariencia, esa falta de urbanidad que Immanuel Kant atribuía a la música ${ }^{22}$. Sin embargo, esa presencia de lo sonoro y la atención a ello, no oculta que la nueva magia sonora se inserta en la esencia del urbanismo mismo: la atención a la ciudad y con ello a las necesidades de la vida urbana. La «Música de Mobiliario» forma parte del diseño urbano, de los espacios de esta vida moderna. Por ello, esta música se inserta en la planificación y ordenación de un territorio que es doble: el que corresponde al espacio en el que el oyente se encuentra y el que pertenecería al espacio interno del propio oyente. Afirmar que la música forma parte de la resolución de las necesidades de la vida urbana implica a su vez admitir que la música es un útil de gestión de poblaciones, de masas ${ }^{23}$.

Entre las propuestas de los futuristas y el presente han pasado cien años. Si los futuristas abogaban por una sensibilidad multiplicada que estaba en consonancia con los ruidos de la vida moderna, con esa multiplicación del sonido que la vida industrial producía, la «Música de Mobiliario» viene en gran parte a ocultar esos sonidos. La vida moderna del siglo XXI calibrada desde la escucha, manifiesta síntomas de un gran ensordecimiento respecto al entorno. Sea a causa de la música convertida en un mueble más, a causa del incremento del volumen sonoro que produce la concentración de automóviles particulares, transportes públicos, obras en las calzadas u otros, el entorno aparece a menudo, como un espacio liso. Esto no significa que el oyente deje de escuchar, la escucha se produce en continuidad, pero, de hecho, simplemente se oye, no se escucha, del mismo modo que se puede mirar sin ver. Con esa escucha las rugosidades del espacio sonoro, sus estriaciones y granos son reducidos a un plano en el que nada surge con volumen, todo parece asimismo convivir en continuidad, formar parte de la misma intensidad sonora.

Contra estas formas de ensordecimiento actúan frontalmente todas esas músicas que siguen experimentando y, entre ellas, los paisajes sonoros. La ex-

22 I. Kant, Crítica del juicio, \& 53, ed. y tr. M. García Morente, Madrid: Espasa Calpe, 1991, p. 290.

23 Acerca de las relaciones entre música y poder $c f r$. C. Pardo, «Experiencias de la discontinuidad», donde se analizan las consecuencias de la continuidad propugnada por las primeras vanguardias entre arte y vida a partir de la denominada música experimental y «El poder de la música. La música del poder», texto en el que se revisan los nexos entre música y poder a partir de la consideración foucaultiana de la sociedad como un archipiélago de poderes diferentes (publicaciones en curso en la Universidad de Salamanca y el Observatori de la Música de Barcelona, respectivamente). 
presión paisaje sonoro fue acuñada por Murray Schafer a finales de los años 60 y surge de la preocupación por los crecientes problemas que genera el ruido en las grandes urbes. Su punto de partida se encontraría más cercano a la ecología acústica que no propiamente a la música, aunque ambas pueden converger. El planteamiento de Schafer condujo a la creación de la World Soundscape Project en la Universidad de Simon Fraser a principios de los años 70. En 1973 se publica The Vancouver Soundscape, el primer trabajo que de modo sistemático recoge el paisaje sonoro de una ciudad. Después, por todo el mundo, le seguirán muchos otros como el paisaje sonoro de Barcelona realizado por Ray Gallon en su Barcelona de la ceba (2003).

El paisaje sonoro de una ciudad constituye una composición sonora que toma como punto de partida los sonidos de la ciudad, unos sonidos que deben permanecer reconocibles para el oyente y que dan cuenta de la cultura sonora de esa ciudad. No es preciso decir que en las grandes ciudades los paisajes sonoros tienden a la uniformidad constituyéndose en términos de Schafer como paisajes $l o-f i$ o de baja definición, frente a los paisajes $h i-f i$ que serían de alta definición dada su riqueza. Sería el carácter lo- $f$ de una ciudad lo que llevaría al ensordecimiento antes señalado, a la falta de atención. Sin embargo, para los futuristas las calles eran $h i-f i$ frente a la sensibilidad adormecida por los sonidos de la música tonal.

El paisaje sonoro se presenta como ejercicio de conciencia sonora que revela los sonidos de la ciudad, la falta de escucha generalizada de los ciudadanos y con ello la falta de preocupación por el ambiente sonoro que conforma la vida en la ciudad. El eslogan publicitario con el que se anunciaba la radio Escuchar es sentir el mundo, cobra otra dimensión con el paisaje sonoro para afirmar con Schafer que el mundo es una composición sonora, un paisaje sonoro indicador de las relaciones sociales.

En la composición sonora del mundo intervienen los ruidos de la calle, de sus gentes, sus máquinas. Se incluyen, asimismo, los medios de reproducción sonora y los instrumentos acústicos y electroacústicos. Pero, en el paisaje sonoro de una ciudad hay miles de oídos que quieren ser ajenos a la ciudad; oídos que transportan su propia banda sonora, primero con sus radiocasetes, después con los walkman, los MP3 y los iPods. Estos medios de reproducción sonora forman parte sin embargo del paisaje de la ciudad y actúan -como el resto de los sonidos-, como indicadores del tipo de vida y de esas relaciones sociales que el paisaje pone en evidencia.

La ubicuidad de lo sonoro permite que la realidad sensible a domicilio pierda sus contornos y pase del hogar al espacio público. La transposición de un sistema de excitaciones individual no queda circunscrita al espacio privado y puede ser reproducido por el oyente a voluntad. La reproducción de lo sonoro y la reproducción de lo sensible pueden conquistar las calles. En continuidad 
puedo escuchar mi música. ¿Pero es ésta, mi música, también «Música de Mobiliario»? ¿Se trata de música industrial que cubre esas necesidades útiles que conducen al confort? Seguramente el abanico de respuestas que podríamos abrir aquí sería amplio y cada una de esas respuestas conduciría al establecimiento de puntos sonoros que denotan diversas relaciones del oyente con el sonido. Pero si una de esas respuestas contempla la música como confort, como vibración agradable que procura un ambiente mientras se atraviesa la ciudad entonces, $m i$ música ha sido transformada en un mueble más, aunque este mueble sonoro sea mi mueble.

Después de que las vanguardias de principios del siglo XX propugnaran la máxima apertura, como la sensibilidad multiplicada propuesta por Russolo, la multiplicación se produce básicamente sobre la repetición. La magia sonora se extiende por doquier y las posibilidades que ofrecen los medios de reproducción alimentan la tendencia a reproducir la escucha aunque, estrictamente, es sabido, la escucha nunca pueda ser repetida.

Los oídos de los futuristas eran oídos excitados por los ruidos de la vida moderna. Sus oídos, poseídos por la excitación, se exponían a un mundo ignoto, se sentían urgidos por la experimentación. A esos oídos, se le podrían sumar aquellos de tantos músicos que buscaban otros caminos para su composición y los oídos que empezaron a organizar los sonidos grabados, también los sonidos sintetizados. Todos ellos y aún muchos más son oídos que se siguen exponiendo, que siguen excitados, pero también son oídos que viven en la continuidad de la escucha, la suya y la de los oyentes que compartirán su música.

El músico es, primordialmente, un oyente y, como tal, está inmerso en la escucha en continuidad. El músico, como el flâneur de Baudelaire, observa esos paseantes que llevan en sus oídos o en sus móviles sus propias bandas sonoras. El músico escucha la banda sonora colectiva de los ruidos de las calles. Desde esa inmersión en la que la distancia entre el hombre anónimo y el hombre que observa, escucha, y transpone esa realidad, se ha hecho mínima, el músico, en el mejor de los casos, con su trabajo atiende a los grados de exposición que puede ofrecer a los que comparten su música. Sin duda, la continuidad de los medios de producción sonora con la de los sistemas de reproducción y todavía más con esos ruidos propios de la vida industrial, no puede ni debe dejar indiferente. Por ello, la música actual da cuenta del modo en que esta continuidad afecta a la escucha que se expone y también a aquella que se complace en hacer de la música un mueble más.

En el origen de la radio, se ha dicho ya, había en juego el establecimiento de un modo de escucha, de ello la urgencia con la que desde diversos frentes apostaron por otros modelos de escucha. Actualmente esa urgencia sigue ahí, en sordina, en un espacio acústico que no es sin embargo, el espacio acústico de 
los antepasados, el de la tribu, aunque contemple algunos elementos en común como el ser una caja de resonancia.

Los sonidos que componen el paisaje sonoro de eso que llamamos mundo y el modo en que los escuchamos son hoy, síntomas privilegiados de la deriva en la que hombres, sonidos y máquinas se multiplican por doquier.

La escucha en continuidad es por ello, uno de los síntomas de esa multiplicación en la que nos complacemos, que nos posee y se nos escapa. 